\begin{tabular}{|l|l|}
\hline AB0658 & PREDICTION OF THE EFFECTIVENESS OF \\
& TREATMENT WITH INFLIXIMAB BASED ON \\
& THE DETERMINATION OF ANTINUCLEAR \\
& ANTIBODIES IN PATIENTS WITH ANKYLOSING \\
& SPONDYLITIS
\end{tabular}

D. Petrovich ${ }^{1}$, D. Roggenbuck ${ }^{2}$, M. Volkava ${ }^{3}$, U. Kundzer ${ }^{4} .{ }^{1}$ Mogilev Regional Hospital, Mogilev, Belarus; ${ }^{2} B T U$, Cottbus-Senftenberg, Germany; ${ }^{3}$ BeIMAPGE, Minsk, Belarus; ${ }^{4}$ Liceum of BSU, Minsk, Belarus

Background: The search for new methods for predicting the effectiveness of treatment for biologics is important issue.

Objectives: To study antinuclear antibodies (ANA) levels during of AS treatment by infliximab and evaluate the influence of ANA on treatment outcome

Methods: The presence of antinuclear antibodies (ANA) in 53 ankylosing spondylitis (AS) patients (44 men (83.02\%), and 9 women $(16.98 \%), 37.19 \pm 9.38$ years (95\% Cl: $34.60-39.78)$ treated with infliximab was determined by indirect immunofluorescence on an automated AKLIDES system in a serum titer of $1 / 80$ initially (before treatment with infliximab) and at week 30 (before 7 administration). Specific autoantibodies were analyzed on the AKLIDES Cytobead platform using the following antigens SS-A 52, SS-A 60, SS-B, ds-DNA, CENP-B, Sm, RNP / Sm. ANA research was carried out at the Brandenburg Technical University (Senftenberg, Germany). Evaluation of the effectiveness of infliximab therapy was carried out by determining ASDAS-CRP at baseline, at the 14th, 30th and 54th weeks.

Results: A positive nuclear type of ANA was determined initially in 2 out of 53 patients $(3.77 \%$ ) (in one case, the type of luminescence was nucleolar, in the other - speckled), at the 30th week of observation, 16 out of 53 patients became seropositive for ANA (30.18\%). The frequency of occurrence of ANA at the 30th week of treatment was significantly higher than the baseline $(p<0.0001)$. Positive results for the determination of specific autoantibodies to at least one nuclear antigen were found in 7 of $16(43.75 \%)$ ANA-positive patients. In all cases, AntiSS-A 60 (100\%) was detected.

In the group of patients in whom treatment with infliximab was ineffective at the 54th week of observation, ANA positivity was observed in 10 (55.5\%). In the case of treatment effectiveness at the 54th week of ANA, positivity was not observed at the 30th week. Differences in the incidence of ANA in patients with effective and ineffective treatment at week 54 were statistically significant $(p<0.0001)$. Anti-infliximab antibodies were significantly more common in ANA-positive patients at week 30 of treatment with infliximab $(p=0.002$, Fisher's exact test).

The appearance of ANA at the 30th week of infliximab therapy was inversely related to the absence of secondary resistance at the 54th week of treatment according to the ASDAS-CRP criteria (OR 0.026 ; $95 \% \mathrm{Cl}$ : $0.002-0.039$; $p=0.0007$ ), which allows us to use the results of the determination of ANA at the 30th week of treatment with infliximab as a predictor of secondary resistance to treatment at the 54th week. When testing the method for predicting secondary resistance to treatment with infliximab at week 54 based on the results of determining ANA at week 30 of treatment in a control sample of 12 patients with AS, it was found that the method is statistically significant $(p=0.0015$, Fisher's exact test).

Conclusion: Assessment of ANA positivity at week 30 of treatment with infliximab can be seen a predictor of the development of secondary resistance to infliximab at the 54th week of treatment.

Disclosure of Interests: None declared

DOI: 10.1136/annrheumdis-2020-eular.5363

\section{AB0659 \\ SECUKINUMAB PROVIDES SIGNIFICANT IMPROVEMENT OF SPINAL PAIN IN PATIENTS WITH AXIAL SPONDYLOARTHRITIS: RESULTS FROM THE 24-WEEK PHASE 3 SKIPPAIN STUDY}

D. Poddubnyy ${ }^{1}$, E. Pournara ${ }^{2}$, A. Zielińska ${ }^{3}$, A. Baranauskaite ${ }^{4}$, A. Muñoz Jimenez. ${ }^{5}$, P. Kumari ${ }^{6}$, B. Schulz ${ }^{2}$, M. Rissler ${ }^{2}$, C. Perella ${ }^{2}$, H. Marzo-Ortega ${ }^{7}$. ${ }^{1}$ Charité - Universitätsmedizin Berlin, Berlin, Germany; ${ }^{2}$ Novartis Pharma AG, Basel, Switzerland; ${ }^{3}$ Medycyna Kliniczna, Warszawa, Poland; ${ }^{4}$ Lithuanian University of Health Sciences, Kaunas, Lithuania; ${ }^{5} \mathrm{H}$. U. Virgen del Rocío, Sevilla, Spain; ${ }^{6}$ Novartis Healthcare Pvt. Ltd, Hyderabad, India; ${ }^{7}$ NIHR Leeds Biomedical Research Centre, LTHT and LIRMM, University of Leeds, Leeds, United Kingdom
Background: Spinal inflammation causing back pain is a hallmark of axial spondyloarthritis (axSpA) mainly affecting the sacroiliac joints and spine. ${ }^{1}$ Spinal pain is the most burdensome symptom resulting in substantial functional limitations and impairment of health-related quality of life.

Objectives: SKIPPAIN (NCT03136861) evaluated efficacy and safety of secukinumab (SEC) in reducing spinal pain in patients (pts) with axSpA who had an inadequate response to NSAIDs.

Methods: SKIPPAIN, a 24 week (wk), randomised, double-blind, multicentre trial, enrolled axSpA pts (aged $\geq 18$ years) with active disease defined by Bath Ankylosing Spondylitis Disease Activity Index (BASDAI) score $\geq 4$ and average spinal pain numerical rating scale (NRS) score $>4$ at baseline (BL) and inadequate response to $\geq 2$ NSAIDs $\geq 4$ wks. The trial had a PBO-controlled period from BL to Wk 8 and a SEC $150 / 300 \mathrm{mg}$ period from Wk 8 to Wk 24. Primary and key secondary endpoints were superiority of SEC $150 \mathrm{mg}$ compared to PBO in achieving average spinal pain score $<4$ on a $0-10$ NRS and BASDAI score $<4$ at Wk 8 , respectively.

Results: 380 axSpA pts (269 (70.8\%) AS and $111(29.2 \%)$ nr-axSpA) were randomised to SEC $150 \mathrm{mg}(\mathrm{N}=285)$ or $\mathrm{PBO}(\mathrm{N}=95)$. Demographic and $\mathrm{BL}$ characteristics are presented in Table 1. Proportion of responders, in terms of average spinal pain, was $31.9 \%$ vs. $20.0 \%$ for SEC vs PBO $(p<0.05)$ and proportion of pts with BASDAI score of $<4$ was $33.3 \%$ vs. $23.2 \%$ for SEC vs PBO $(p<0.05)$, respectively at Wk 8 (Table 2$)$. After Wk 8 , responder rates increased with SEC treatment. No unexpected safety events were reported.

Conclusion: Secukinumab provided significant improvement of spinal pain in pts with axSpA. SEC was well tolerated with a safety profile consistent with previous reports. ${ }^{2}$

References:

[1] Danve A \& Deodhar A. Clin Rheumatol. 2019;38:625-34.

[2] Deodhar A, et al. Arthritis Res Ther. 2019;21(1):111.

Table 1. Patient Demographics and BL Characteristics

\begin{tabular}{lcc}
\hline Characteristic & $\begin{array}{c}\text { SEC 150 } \mathbf{~ m g} \\
\mathbf{N}=\mathbf{2 8 5}\end{array}$ & $\begin{array}{c}\text { PBO } \\
\text { N = 95 }\end{array}$ \\
\hline${\text { Age }(\text { years })^{1}}^{1}$ & $42.3(11.9)$ & $40.9(12.2)$ \\
Female $^{2}$ & $106(37.2)$ & $39(41.1)$ \\
Time since onset of back pain (years) $^{1}$ & $13.2(10.1)$ & $12.3(9.6)$ \\
HLA-B27 positive $^{2}$ & $233(81.8)$ & $76(80.0)$ \\
${\text { hsCRP }\left(\mathrm{mg} / \mathrm{L}^{1}\right.}^{1}$ & $13.0(21.5)$ & $13.2(23.5)$ \\
Elevated hsCRP $\left(>5\right.$ mg/L) $^{2}$ & $140(49.1)$ & $49(51.6)$ \\
Previous exposure to TNF-a inhibitors $^{2}$ & $34(11.9)$ & $11(11.6)$ \\
Spinal pain NRS Score, 0-10 (average) $^{1}$ & $7.27(1.37)$ & $7.31(1.31)$ \\
Spinal pain NRS Score, 0-10 (nocturnal) $^{1}$ & $7.31(1.42)$ & $7.40(1.35)$ \\
Spinal pain NRS Score, 0-10 (total) $^{1}$ & $7.23(1.51)$ & $7.22(1.48)$ \\
BASDAl $^{1}$ & $7.09(1.22)$ & $6.91(1.38)$ \\
ASDAS $^{1}$ & $3.75(0.89)$ & $3.67(0.84)$ \\
Peripheral arthritis $^{2}$ & $104(36.5)$ & $30(31.6)$ \\
\hline
\end{tabular}

${ }^{1}$ mean (Standard Deviation), ${ }^{2} \mathrm{n}(\%)$.

hsCRP, high-sensitivity CRP; $N$, number of randomized pts; $n$, number of evaluable pts; NRS, numerical rating scale

Table 2. Inferential Analysis of Achieving Spinal Pain and BASDAI Score $<4.0$ Using Logistic Regression Model at Wk 8

\begin{tabular}{|c|c|c|c|c|c|}
\hline Variable & $\begin{array}{l}\text { Treatment } \\
\text { Group }\end{array}$ & $\mathrm{n} / \mathrm{N}(\%)$ & $\begin{array}{l}\text { Odds ratio } \\
\text { versus PBO }\end{array}$ & $95 \% \mathrm{Cl}$ & P-value \\
\hline $\begin{array}{l}\text { Spinal Pain NRS } \\
\text { Score (Average) }\end{array}$ & $\begin{array}{c}\text { SEC } 150 \mathrm{mg} \\
\text { PBO }\end{array}$ & $\begin{array}{c}91 / 285 \text { (31.9) } \\
19 / 95(\mathbf{2 0 . 0 )}\end{array}$ & 1.89 & $(1.08,3.33)$ & 0.0264 \\
\hline $\begin{array}{l}\text { Spinal Pain NRS } \\
\text { Score (Nocturnal) }\end{array}$ & $\begin{array}{c}\text { SEC } 150 \mathrm{mg} \\
\text { PBO }\end{array}$ & $\begin{array}{c}77 / 285 \text { (27.0) } \\
17 / 95 \text { (17.9) }\end{array}$ & 1.72 & $(0.95,3.10)$ & 0.0720 \\
\hline $\begin{array}{l}\text { Spinal Pain NRS } \\
\text { Score (Total) }\end{array}$ & $\begin{array}{c}\text { SEC } 150 \mathrm{mg} \\
\text { PBO }\end{array}$ & $\begin{array}{c}92 / 285 \text { (32.3) } \\
16 / 95(\mathbf{1 6 . 8 )}\end{array}$ & 2.38 & $(1.31,4.31)$ & 0.0043 \\
\hline BASDAI score & $\begin{array}{c}\text { SEC150 mg } \\
\text { PBO }\end{array}$ & $\begin{array}{c}95 / 285 \text { (33.3) } \\
22 / 95 \text { (23.2) }\end{array}$ & 1.75 & $(1.01,3.04)$ & 0.0466 \\
\hline
\end{tabular}

P-values are from a Logistic regression model with treatment as the principle factor and prior exposure to TNF inhibitors and naïve/inadequate responders to TNF inhibitors as stratification factors.

Missing values were imputed as non-responders. N, Number of randomised pts; $n$, Number of pts who are responders/evaluable pts. 